\title{
A RESIGNIFICAÇÃO DO RURAL E AS RELAÇÕES CIDADE-CAMPO: UMA CONTRIBUIÇÃO GEOGRÁFICA.
}

João Rua.

Professor da Universidade Estadual do Rio de Janeiro Professor da Pontifice Universidade Católica - RJ joaorua@vetor.com.br

\section{Resumo}

Este ensaio pretende contribuir para o debate acerca da conceptualização do rural, travado por alguns dos principais autores da teoria social crítica, que focalizam este tema, e como eles teorizam sobre as territorialidades resultantes da interação entre o urbano e o rural. Os elementos obtidos nas principais abordagens, sugerem que uma outra dialética pode conduzir-nos à idéia de "urbanidades no rural", considerando-as como manifestações de espaços híbridos, nos quais urbano e rural integram-se e todas as formas de combinações. Esta abordagem pode mostrar alternativas analíticas que atenuem as limitações das perspectivas principais.

Palavras-chave: rural, urbanidades no rural, novas ruralidades

\begin{abstract}
This paper aims to contribute to the debate about the conceptualization of the rural performed by some of the main authors of the critical social theory that focus on this theme, and how they theorize about the new territorialities resultants from the rural-urban interactions. The elements obtained in main approaches suggest that an other dialectic may lead to the idea of "urbanities on rural areas" considering this ones as manifestations of hybrid spaces, in which the urban and rural intertwine and interact in all manners of combinations. This approach may show other analytical alternatives to attenuate the limitations of the main perspectives.
\end{abstract}

Key Words: rural, urbanities on rural areas, new ruralities.

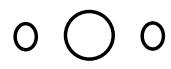

Torna-se difícil, se não impossível compreender as relações urbano-rural e cidade-campo sem integrálas ao movimento de constituição do exercício do poder e da hegemonia (econômicos, políticos, culturais e simbólicos) numa construção de novas representações do espaço, integradas às revoluções que têm marcado a modernidade: revolução técnico-científica, revoluções burguesas e revolução industrial em que aquelas espacialidades viram seus papéis serem alterados em função da inserção, nos movimentos referidos, dos atores nelas atuantes. Também, desde já, é preciso ressaltar que esse processo é contraditório e admite múltiplas manifestações. Ora as classes sociais rurais (grandes proprietários e camponeses) são vencidos, ora são cooptados; ora conseguem se integrar ao bloco hegemônico, ora conseguem manifestar suas vozes afirmando espaços de representação que se opõem às representações do espaço dominantes.

Escreve Léfèbvre (1986, p. 53) que as representações do espaço têm considerável peso e influência na produção do espaço, principalmente levando em conta que correspondem a um sistema de signos, símbolos e códigos de representação dominantes em uma sociedade e que estão relacionados ao exercício do poder e à conformação do espaço abstrato, domínio do Estado e do poder hegemônico.

Esse poder, centrado na cidade moderna capitalista, como veremos, vem impondo símbolos, códigos e signos territorializados tanto ao "rural" quanto ao "urbano", que têm, como vimos, seus papéis alterados pelos atores produtores dessas espacialidades redefinido suas identidades em cada momento do movimento do todo social.

Concordamos com Haesbaert (2005, p. 2) quando escreve que embora Lefèbvre se refira, quase sempre, 
a espaço e poucas vezes a território, é fácil perceber que não se trata de um espaço no sentido genérico, e que se trata, isso sim, de um espaço-processo, um espaço socialmente construído, portanto territorializado. Ou seja, qualquer projeto no espaço que é expresso por uma representação revela a imagem desejada de um território, de um lugar de relações, de apropriações e dominações.

Este tipo de representação tem a capacidade de dar conta da dinâmica das ações empreendidas no espaço e isso é importante, porque ela está em constante transformação ao longo da história (bem como as relações de poder), influenciando a permanente redefinição desse espaço e, consequentemente, do território. É a essa concepção de espaço, feito território, que nos referiremos daqui em diante.

As reflexões que aqui desenvolvemos dão continuidade às que explicitamos em trabalhos anteriores (RUA, 2002a e 2002b) das quais, aqui, reapresentaremos alguns trechos ${ }^{1}$.

Neste artigo tem-se como objetivo principal retomar aquela discussão enfatizando, desta vez, as múltiplas interações entre o rural e o urbano, balizadas pelos diversos momentos do capitalismo contemporâneo e criadoras de territorialidades que ainda estão por definir. Fica claro, para nós, que se trata de duas escalas de análise: uma que abarca todo o território, em que o "urbano" se manifestará ideologicamente, comportamentalmente, com representações homogeneizadoras; outra escala será a das interações urbanorurais, em que espaços híbridos serão gerados como frutos particulares de tais interações. A empiria, sempre necessária, pelos questionamentos que coloca, refere-se ao território fluminense - principalmente à Região Serrana e ao Norte do estado - realidades bastante conhecidas e que, com suas particularidades, desafiam os pesquisadores a explicarem as relações urbano-rural em situações tão marcadamente metropolizadas como ocorre no estado do Rio de Janeiro.

\section{Rural e Urbano, Cidade e Campo - uma difícil definição.}

Até hoje tem predominado uma visão espacial da desigualdade, em que os espaços periféricos/rurais, dominados, seguem o modelo dos espaços centrais/urbanos, numa dicotomia adiantado/atrasado. Tal visão do rural tem atravessado a maioria das análises efetuadas, inclusive aquelas oriundas de Marx que, ao estudar as relações cidade-campo não escapou da visão urbanocêntrica (principalmente em suas primeiras obras) que dá primazia à cidade em sua luta contra o campo e corroborou uma imagem retrógrada do campo constituindo-o como o "outro" da cidade (Botelho, 2005a, p.146) 2 .

Em trecho retomado por diversos autores, Marx e Engels (1998, p, 55), escrevem que "a cidade constitui o espaço da concentração, da população, dos instrumentos de produção, do capital, dos prazeres e das necessidades, ao passo que o campo evidencia o oposto, o isolamento, e a dispersão".

O que se percebe é que não está evidente a dialética campo-cidade, já que se excluem mutuamente. Segundo Botelho (2005a, p. 151), é possível encontrar tal dialética nas obras posteriores de Marx, mas que, mesmo nelas, "a perspectiva de correlacionar campo com isolamento e dispersão, de um lado, e cidade com concentração, de outro, permanecerá na obra marxiana e terá ressonâncias em sua visão sobre a revolução". Acrescentamos que essa ressonância virá até nossos dias, manifestada na visão da maioria dos autores marxistas acrescida de uma visão homogeneizadora do espaço em que cidade e campo se verão fundidos, numa única espacialidade "urbanizada".

Neste ensaio procuraremos demonstrar que a Geografia pode resgatar a diferença e enfatizar que cada um tem sua própria história, que se materializa em espacialidades/territorialidades próprias. A desigualdade mata as outras vozes, territorializadas em reivindicações específicas. A diferença resgata-as. A desigualdade vê os outros espaços/territórios como simples variações do nosso, situado como referência. A Geografia da diferença, por seu lado, necessita da co-existência, da multiplicidade, como ressalta Massey (1999, p. 281). Lembra-nos, essa autora, que o espaço, além de produto de interrelações, como 
largamente tem sido demonstrado, é constituído através de um processo de interações e que se torna a esfera da existência da multiplicidade onde distintas narrativas co-existem e que sem o espaço essa multiplicidade seria impossível, ao mesmo tempo em que o espaço só existe se existir a multiplicidade pois os dois são co-constitutivos (p.279). Prossegue lembrando que o espaço está sempre num processo de devir, permanentemente sendo feito, nunca está finalizado. Será esta a base conceitual para a nossa reflexão sobre os espaços, tornados territórios pelos atores que lhes atribuem ressignificações.

É nessa perspectiva que pretendemos caminhar, tentando explicitar neste trabalho, a percepção do "rural" e do "urbano" como resultado de interações múltiplas, transescalares, não-hierarquizadas e mostrando novas possibilidades espaciais a serem construídas num movimento histórico em que a homogeneização e a diversidade não obscureçam a sua dialética.

Outra base teórica, de referência obrigatória é Edgar Morin (2000) ao trazer a complexidade que a ciência sempre recusou (mesmo com ela convivendo nos falsos antagonismos empirismo x racionalismo; imaginação x verificação) para o centro do debate acadêmico e procurando transformar o (re)conhecimento da complexidade em pensamento da complexidade.

Buscando um método multidimensional, pretende-se compreender o espaço (rural), percebendo-o como um espaço híbrido (será explicado mais à frente) pleno de possibilidades e onde experiências inovadoras (algumas com características de resistências) podem ser desenvolvidas.

Se em casos como da Inglaterra, França ou Estados Unidos, por exemplo, as estruturas antigas latifundiárias (quando existentes) foram parcialmente derrotadas, dando lugar a formas mais democráticas de relação com a terra (embora sem abranger a totalidade do território desses países), no Brasil, o que aconteceu foi a manutenção das fortes raízes agrárias e de uma ruralidade autoritária (MOREIRA, 2003, p. 129) que se firmou na quase totalidade de nosso país. A grande propriedade agrária exerce forte domínio sobre o território e tem, até agora, imposto sua força política em sucessivos pactos com os setores dominantes do bloco hegemônico, sem, entretanto, deixar esse bloco. Basta lembrar o contexto da promulgação da Lei de Terras de 1850 e os arranjos institucionais posteriores à Revolução de 1930, ao golpe de 1964 e à regulamentação da Constituição de 1988. É a força dessa hegemonia traduzida nas relações econômicas, políticas, culturais e simbólicas que vai marcar aquilo a que alguns chamam de modernização conservadora que privilegia alguns setores e algumas parcelas do espaço (de acordo com os agentes sociais nele intervenientes) em detrimento de outras. Pode se perceber que o capitalismo integra sem homogeneizar espacialmente ou socialmente.

Assim espaço rural e espaço urbano, cidade e campo integram-se à mesma racionalidade espacial que marca a sociedade contemporânea, organizada a partir da cidade, da indústria e, atualmente, da terciarização - bases operativas privilegiadas para a reprodução do capitalismo em sua produção histórica e para a constituição da visão burguesa de mundo. Este processo transescalar tem abrangido o planeta (Ocidentalização do Mundo), a nação (hegemonia do Sudeste urbano-industrial) e a multiescalaridade das relações cidade-campo - todas elas dicotômicas, hierarquizadoras e polarizadoras. As dicotomias rural/ urbano e cidade-campo evidenciadas pela análise feita pela sociologia funcionalista ${ }^{3}$ norte-americana (e, também, na Geografia) tem marcado grande parte das discussões efetuadas e acabou por influenciar na visão do rural como um resíduo e na busca de indicadores que distinguissem o rural e o urbano.

A polarização construída na modernidade e exercida pela cidade concentrou nela poder político, capital, cultura, moda, etc e projetou um modo de viver, pensar e agir urbano que, cada vez mais, tem subordinado o campo - visto como atrasado, incivilizado, rústico. Estas imagens são reforçadas pela linguagem: civiscivil-civilizado; urbs-urbano-urbanidade; polis-polido-educado-político; burg-burguês. O próprio termo cidade (em suas múltiplas origens) é apropriado para criar a representação social do "burguês polido, 
político, educado, cidadão". O rural - rus, ruris, em latim, que derivou em rude - passa a ser visto como o "outro, nessas representações. Com os estudos a respeito do desenvolvimento, posteriores à Segunda Guerra Mundial, em que se enfatizou o tecnológico em detrimento do social e das comunidades (visão predominante até hoje), o rural foi sendo construído como sinônimo de agrícola, o que acelerou, mais ainda, as dicotomias já existentes.

Também na política oficial o rural tem sido percebido como agrícola (ligado apenas à produção); a agricultura de exportação, tecnicamente avançada, tem sido privilegiada, enquanto a agricultura de mercado interno foi chamada de "agricultura de subsistência" e considerados os pequenos agricultores (proprietários ou não) como incapazes de acompanhar o progresso técnico, econômico e social.

O Estado, ao viabilizar os chamados "complexos agroindustriais" e favorecer o empresariado rural em detrimento dos produtores familiares camponeses tem mantido os velhos pactos entre os setores do bloco hegemônico, contando sempre com a resistência, algumas vezes manifestada com violência, desses camponeses que desenvolvem estratégias de sobrevivência particulares ou coletivas, quando integrados a movimentos sociais rurais (embora não exclusivamente com contingentes rurais) como o MST, o de maior expressão até o momento.

O caráter contraditório do capitalismo se manifesta, mais uma vez, ao não prescindir de manter (e muitas vezes ampliar) relações não-capitalistas de produção, como demonstra Oliveira (1991 e 2001). Esses produtores familiares camponeses estão integrados diretamente à produção capitalista, seja como não-proprietários, seja como proprietários. A integração desses produtores aos complexos agroindustriais e aos mercados tem sido viabilizada, pelos interesses do empresariado rural, com base em créditos bancários, difusão tecnológica e ampliação de mercados de bens de produção industriais para a agricultura.

As mudanças no modelo produtivo e organizacional no campo compõem transformações mais amplas na sociedade brasileira (por sua vez integradas a alterações sentidas em escala global) que marcam as últimas duas décadas. Define-se uma lógica capitalista em que novas representações do espaço emergem e vão ser difundidas como "um novo rural". Na verdade são novas imagens, novos sentidos para o espaço rural que mantêm a visão produtivista, até agora dominante, mas que se traduzem em novos qualificativos para outras relações entre o espaço urbano e o rural e entre a cidade e o campo.. Estas novas relações remetem para uma outra conceituação de urbano e rural, mas também de agrícola. Rural torna-se, cada vez mais, diferente de agrícola. Ao mesmo tempo, distingue-se cidade e urbano explicitando a crescente complexidade que marca tais relações. Rural e urbano integram-se mas sem se tornarem a mesma coisa, já que preservam suas especificidades.

Moreira (2003, p. 132), sintetiza bem esse processo de recriação do rural, com base na pluriatividade e na perspectiva de uma multifuncionalidade do território (defesa dos patrimônios naturais e culturais). Para o autor ocorre uma valorização da cultura local e a dinamização de agroindústrias associativas de agricultores familiares. Esses processos de revalorização do mundo rural, ressignificando-o, consolidam atividades rurais e urbanas em cidades interioranas. Essas ressignificações têm influído nas representações que marcam o rural, sendo, por elas, também, afetadas provocando a necessária revisão conceitual de "rural" e "urbano" procurando incorporar as lógicas atuais que marcam o espaço, como um todo.

Em Rua (2002a) fizemos uma discussão com base nas principais posições teóricas a respeito das relações urbano-rural e cidade-campo, procurando elucidar os cenários que, para esses autores se apresentavam, ao elaborarem a análise desses que, para alguns, constituem conjuntos sócio-espaciais. Referimo-nos, tão somente, a determinados autores integrados a uma visão crítica da sociedade capitalista, principalmente daqueles que baseiam suas análises numa fundamentação influenciada pelas idéias de Marx, naquilo que se refere às relações cidade-campo, concordando ou não com elas ${ }^{4}$. Tentaremos sintetizar algumas das 
posições analíticas que tomaremos como referência para refutação ou incorporação.

Uma primeira "vertente" parece aproximar Octávio Ianni, José Graziano da Silva, Milton Santos e Henri Lefébvre, como exemplos de uma certa leitura das formulações marxianas e marxistas, centradas na cidade e no urbano como bases organizativas do espaço contemporâneo. Embora com diferenças significativas nas suas posições, decidimos colocá-los juntos no que denominaremos "abordagem clássica". Ianni (cf. RUA, 2002a, p. 30) afirma que se dissolvem as fronteiras entre campo e cidade pois:

Acontece que faz tempo que a cidade não só venceu como absorveu o campo, o agrário, a sociedade rural. Acabou a contradição cidade e campo, na medida em que o modo urbano de vida, a sociabilidade burguesa, a cultura do capitalismo, o capitalismo como processo civilizatório invadem, recobrem, absorvem ou recriam o campo com outros significados.

Graziano da Silva, embora sem explicitar, como Ianni, o fim do rural, advoga "a necessidade de políticas públicas que desprivatizem os espaços rurais agropecuários no país, criando povoados rurais urbanizados"(1999, p. 78). Em outro momento, ao analisar a delimitação do rural e do urbano no Brasil $(1999$, p. 57) demonstra como o crescimento das atividades não-agrícolas tem provocado uma urbanização do meio rural não contemplada pelos critérios dos órgãos oficiais. Essa urbanização do campo brasileiro se daria, segundo o autor, tanto nas áreas de produção agrícola modernizada (integradas, plenamente, à lógica produtiva urbana) quanto nas áreas "tradicionais" para onde se deslocariam atividades não-agrícolas (1997, p.51). O conceito de rurbano, que vem divulgando, dá bem essa dimensão do rural urbanizado.

Algumas críticas efetuadas a esses autores residem no fato de que suas formulações não contemplam as diferenças existentes no próprio processo de modernização deixando de perceber as especificidades e contradições nele contidas; atribuem uma racionalidade comum a todas as estratégias que estão por trás de práticas idênticas; não enfatizam as continuidades históricas entre os processos antigos e atuais, atribuindo a todos o caráter de novidade.

Embora a análise de Graziano da Silva seja referência para todos os estudiosos do rural e das relações urbano-rurais, parece-nos que há um certo exagero na generalização homogeneizadora do "novo rural" (expressão consagrada pelo autor), bem como no tom otimista que divulga ao se referir às medidas compensatórias que deveriam ser difundidas em substituição a uma reforma agrária de caráter estrutural. Para ele, a reforma agrária é necessária, mas não precisa ter um caráter essencialmente agrícola, especialmente no Centro-Sul do país. Seria uma forma de ocupação que combinasse atividades agrícolas e não-agrícolas, necessitando de pouca terra e aceleradora da urbanização do rural (Graziano da Silva. 1998, p. 122, citado em RUA, 2002a).

Outra referência fundamental, para nós geógrafos, é Santos (1993) que, ao analisar a nova urbanização, demonstra a diversificação e a complexidade do processo e chama atenção para a necessidade de distinguir o agrícola do rural, ao mostrar a difusão do urbano no território brasileiro. Para ele, atingimos a urbanização da sociedade e a urbanização do território, depois de longo período de urbanização social e territorialmente seletiva. Considera cidade e campo como formas no espaço e defende que urbano e rural evidenciariam o conteúdo social de tais formas. Com base nas idéias desse autor, embora sem corroborar sua perspectiva de urbanização total da sociedade (partilhada com Léfèbvre, como veremos), percebemos que deve ser enfatizada uma outra maneira de ver o rural oposta a esse trabalho secular de purificação, fundado em dois pólos distintos - urbano e rural, cidade e campo, retomando a idéia de um espaço híbrido, isto é, um conjunto inseparável de sistemas de objetos e sistemas de ações (Santos,1996, p. 72) que marcam o momento atual fundindo o urbano e o rural numa única espacialidade.

Essa idéia de hibridez, buscada em Latour (1994, p. 16), vai ser essencial para a busca da identidade 
do rural na contemporaneidade. Uma série de "mistos" que vão definir tal identidade em que o rural não é (mais) plenamente rural por que incorpora "urbanidades" que com ele vão interagir e dar lugar a territorialidades outras, que resta por definir.

Henri Léfébvre coloca-se como um dos mais importantes pensadores do século XX. São fundamentais as suas reflexões sobre a importância do espaço para a existência humana e mesmo colocado nesta vertente analítica, vai nos oferecer uma acurada observação sobre as relações urbano/rural e cidade/campo que não cabem no rótulo "urbanização do rural", idéia fundante para os autores dessa "abordagem clássica".

Sua análise é muito marcada pela idéia de que a industrialização promovera a urbanização da sociedade e, no movimento de construção da urbanidade, havia também gerado forças que uma nova revolução deveria libertar (a revolução urbana). Léfèbvre ao se referir a revoluções, provoca os socialismos de estado ao escrever que uma revolução que não produz um espaço novo não vai fundo nela mesma, pois não muda a vida. Só altera as superestruturas ideológicas, as instituições, os aparelhos políticos (1986, p. 66).

Na mesma obra (p. 67) deixa claro que a urbanização inevitável da sociedade não ocorreria em detrimento de setores, acentuando as desigualdades de crescimento e desenvolvimento; ela ultrapassaria a oposição cidade-campo sem degradar um em detrimento do outro.

Em outro momento (1999a, p. 49), interpretando Marx, escreve que "o sujeito da história é incontestavelmente a cidade" onde estaria a concentração (população, instrumentos de produção, capital etc), logo tudo o que faz com que uma sociedade seja uma sociedade, continuando a explicitar o pensamento de Marx. Parece, assim, colocar-se ao lado dos outros autores dessa linha analítica e, mesmo quando faz um retrospecto histórico da cidade nas diferentes divisões de trabalho, escreve que o Estado passa a atuar no interior do seu território a partir de um determinado sistema urbano. Em famosa passagem do livro a Revolução Urbana, Léfèbvre (1999b, p. 17) escreve que:

A concentração da população acompanha a dos meios de produção. O tecido urbano prolifera, estendendose, corrói os resíduos da vida agrária. Estas palavras, "o tecido urbano" não designam de maneira restrita, o domínio edificado nas cidades, mas o conjunto de manifestações do predomínio da cidade sobre o campo. Nessa acepção, uma segunda residência, uma rodovia, um supermercado em pleno campo, fazem parte do tecido urbano.

Aqui, como se vê, já se explicitam diferenças com relação à maioria dos autores que advogam a "urbanização do espaço rural"

É na concepção de urbano demonstrada por Léfèbvre, nessa obra, que baseamos a nossa idéia de "urbanidades no rural", que explicitaremos mais à frente. É, também, com a idéia de sociedade urbana como devir, como possível e virtual, que trabalharemos para perceber a "urbanização da sociedade", em que o urbano ultrapassa a cidade e se instala na escala do território.

Estes serão importantes (não únicos) balizamentos de nossa análise, incorporando a necessária escalaridade à análise lefevriana. Se bem que não concordemos totalmente com a visão do autor a respeito da "urbanização inevitável" e da ampliação da oposição urbanidade-ruralidade em lugar do seu desaparecimento (2001, p. 69), será com Léfèbvre que mais dialogaremos, ao longo do trabalho, ao discutirmos qual o caráter dessa "urbanização" e em que escalas se manifesta no território.

A espacialidade contraditória urbano-rural (e não cidade/campo) foi muito bem capturada por Sposito (1999, p. 84) quando reflete sobre as redefinições das dialéticas cidade-urbano e cidade-urbanidade. Escreve a autora supracitada:

Se as relações cidade-campo não expressam simetricamente aquelas entre o urbano e o rural, porque as relações que se estabelecem a partir das cidades, os símbolos e signos que nelas e através delas expressam 
o que é urbano estão além das cidades, é preciso refletir sobre qual é o sentido dessa urbanização e em que medida a reprodução do urbano pode gerar não o fim da distinção cidade-campo, mas a ausência da cidade na perspectiva de um conteúdo de urbanidade (SPOSITO, 1999, p. 84).

Podemos concordar que há uma escala da urbanização que abrange todo o território, mas que também existem outras escalas em que acontecimentos locais, fruto de leituras particulares em que as interações local/global, interno/externo, urbano/rural, terão de ser contempladas nas análises a serem efetuadas.

Em geral, para essa vertente analítica, com a expansão do capitalismo, o rural se "moderniza", isto é, se "urbaniza", adquirindo, assim, um sentido de pertencimento, de inclusão e de presença do Estado, através das infraestruturas construídas, que constituiriam a materialização da urbanização.

Esta posição (da integração urbano-rural, homogeneizadora, mesmo que virtual e, para alguns de urbanização iminente e irreversível do rural), se bem que apoiada pela maioria dos autores, encontra diversos opositores, também de posicionamento social-crítico, como Maria José Carneiro, Roberto José Moreira, José Eli da Veiga, Ricardo Abramovay e Sérgio Schneider (dentre outros) que, apesar da enorme diversidade poderíamos denominar de vertente analítica que se apóia nas "novas ruralidades".

Carneiro (1998), por exemplo, vê o rural como uma categoria social e não como um recorte espacial. Também enfatiza a multifuncionalidade e a pluriatividade como estratégias de sobrevivência da família rural graças às atividades não-agrícolas a ela associadas e ao uso variado das unidades rurais. Para Carneiro "é precipitado concluir que o processo de expansão da racionalidade urbana resultaria na dissolução do agrário e na tendência à transformação uniformizadora das condições de vida no campo" (1998, p. 54).

A sua argumentação prossegue, quando diz que não podemos entender a ruralidade hoje somente a partir da penetração do mundo urbano-industrial no que era definido tradicionalmente como "rural", mas também do consumo pela sociedade urbano-industrial, de bens simbólicos e materiais (a natureza como valor, e os produtos "naturais", como exemplo) e de práticas culturais que são reconhecidas como sendo próprias do mundo rural (Carneiro, citada em RUA, 2002a, p. 31).

Para a autora supracitada há uma maior interação entre os dois ambientes culturais (rural e urbano), mas, ao invés de acarretar um inevitável fim do rural, pode ocorrer um reforço da ruralidade, o que demandaria, pelo menos, um certo cuidado ao se anunciar o fim do rural. Fala mesmo de um certo "renascimento" do rural, que marcaria a dinâmica atual das trocas sociais e econômicas entre campo e cidade.

Autor com posição singular (mesmo que se alinhe nas concepções gerais deste grupo é Roberto José Moreira que aponta para a construção de identidades múltiplas no rural e refutando as posições essencialistas. Defende a idéia de que a natureza concebida como espaço rural, por sua localização territorial e por suas potencialidades ecossistêmicas, é uma realização da cultura (1999, p. 249). Demonstra que os valores culturais relacionados ao espaço rural estão integrados à cultura hegemônica que (re)constrói uma outra ruralidade (e da natureza), num permanente processo de ressignificação portando novas noções de espaço. Assim, o rural estaria deixando de ser visto como atrasado, em vias de desaparecimento para tornar-se um rural-natureza, símbolo da civilidade contemporânea, associada às novas ruralidades.

Trata-se de espacialidades interagentes pois "se vivencia a incorporação de populações urbanas no espaço rural, de maneira que a dimensão territorial é destacada, já que, o território se constitui na incorporação de elementos simbólicos e materiais urbanos no espaço rural" (MOREIRA, 2002, p. 54). O autor continua desenvolvendo uma concepção de território que muito o aproxima das discussões sobre esse conceito, travadas na Geografia de hoje. Escreve que "o território refere-se aos contextos sociais, culturais e espaciais em que acontece a interconexão entre o urbano e o rural, isto é, quando não 'é possível considerar o urbano sem o rural e vice-versa"(p. 54).

As formulações desse autor auxiliam-nos a perceber o rural em suas multiplicidades e virtualidades 
em que podem conviver diversas narrativas: a constituição cultural da imagem do rural; a intenção de mostrar o rural de acordo com o lugar que ocupou nos diferentes projetos políticos e em tempos históricos distintos; a compreensão das políticas para o mundo rural como parte dos processos de legitimação e de dominação urbano-industrial. Para esse autor, o rural se manteria como recriação do urbano em que as ruralidades seriam identidades abertas e múltiplas, integradas a assimetrias de poder associadas aos processos sociais.

Em Rua (2002a), já incluíamos nessa vertente analítica (das novas ruralidades) os autores José Eli da Veiga e Ricardo Abramovay ${ }^{5}$ que, ao estabelecerem o modelo da OCDE $^{6}$ como parâmetro para se pensar o rural no Brasil, enfatizam demasiadamente a dimensão político-administrativa (normativa), em detrimento de outras dimensões (simbólica, cultural, natural) exigidas para uma análise mais integradora do território.

Veiga combina densidade demográfica e tamanho populacional partindo da premissa de que se aprofundam as diferenças entre o urbano e o rural e que esta diferenciação espacial é importante para as estratégias de desenvolvimento, não se atrelando este à urbanização, já que pode haver uma área rural que se desenvolva, sem que se torne não-rural (VEIGA, 2001). Chama atenção para um mito do Brasil hiperurbanizado, mostrando a importância dos serviços e da indústria na economia rural e esclarece que enquanto isto não for levado em conta, "continuarão muito precárias todas as tentativas de formular uma nova agenda de desenvolvimento para o país". Em seu ponto de vista há muitas razões para se afirmar que está em curso uma forte valorização da ruralidade, em vez de sua supressão por uma suposta completa urbanização e que não estaria desaparecendo a histórica contradição urbano-rural, (VEIGA, 2004, p. 9192). É aí que ele justifica a sua permanência neste grupo de autores que, em geral postula a permanência do rural e de suas especificidades.

Uma outra referência, neste curto ensaio, é Abramovay (2000 e 2001) que, ao discutir funções e medidas da ruralidade no desenvolvimento contemporâneo, baseado, também, nas formulações da OCDE, lança luzes novas na discussão das relações rural-urbano. Combate a idéia de que o rural é residual em relação ao urbano e lembra que é preciso definir o meio rural de maneira a levar em conta tanto a sua especificidade (isto é sem encarar seu desenvolvimento como sinônimo de "urbanização"), como os fatores que determinam sua dinâmica, (isto é, sua relação com as cidades). Os impactos políticos da resposta a esta pergunta teórica e metodológica são óbvios: se o meio rural for apenas a expressão, sempre minguada, do que vai restando das concentrações urbanas, ele se credencia, no máximo, a receber políticas sociais que compensem sua inevitável decadência e pobreza. Se, ao contrário, as regiões rurais tiverem a capacidade de preencher funções necessárias a seus próprios habitantes e também às cidades - mas que estas próprias não podem produzir - então a noção de desenvolvimento poderá ser aplicada ao meio rural” (2000, p. 7).

Em seguida faz uma discussão das insatisfatórias fronteiras entre o rural e o urbano e, ao valorizar o conceito de espaço desenvolve uma análise bastante acurada ao incorporar a relação com a natureza, a importância das áreas não densamente povoadas e a dependência do sistema urbano. Por fim comenta alguns métodos de definição do rural que se baseiam na importância das áreas não densamente povoadas e no tipo de relações que elas mantêm com as cidades. Explicita a idéia de que um território representa uma trama de relações com raízes históricas, configurações políticas e identidades que desempenham um papel ainda pouco conhecido no próprio desenvolvimento econômico. Identifica-se com a linha da permanência do rural ao escrever que ruralidade é um conceito de natureza territorial e não setorial, não podendo ser encarada como etapa do desenvolvimento a ser vencida pelo avanço do progresso e da urbanização. Enfatiza os três atributos básicos que vê no rural contemporâneo: uma relação com a natureza, uma relativa dispersão populacional, e a relação com as regiões urbanas onde se encontra o 
centro nervoso do processo de desenvolvimento.

Utilizar modelos aplicados em países desenvolvidos para realidades tão diversas como a brasileira, em geral, e a fluminense em particular pode nos levar a conclusões equivocadas. Afinal, em que país central, com as dimensões territoriais do estado do Rio de Janeiro, existe tamanha macrocefalia metropolitana, com um peso político, econômico, demográfico, cultural tão concentrado numa única cidade. No estado do Rio de Janeiro observa-se uma verdadeira metropolização do espaço que imprime ao território características antes exclusivas da região metropolitana, fazendo com que não só as práticas sociais, mas, inclusive as identidades dos lugares, fiquem sujeitas aos códigos da metrópole, como bem escreve Lencioni (2003, p.35). Só este fato já nos faria relativizar a aplicação dos indicadores da OCDE em nosso estado. Aspecto mais importante ainda, é o risco que se corre ao distinguir estatisticamente urbano e rural e, com isso, obscurecer o movimento contraditório que marca as interações espaciais na atual fase de unificação diferenciadora do espaço do capital.

Reconhecemos, entretanto, que é necessário buscar formas de analisar o real e, para isso, utilizar os instrumentos disponíveis, mas com muito cuidado. A estas críticas ${ }^{7}$ voltaremos mais adiante.

Referência obrigatória, nesta segunda vertente analítica (manutenção das especificidades do rural) é Sérgio Schneider (Schneider, 2003) por mostrar, a partir da sociologia, mas com fortes vínculos com a Geografia, a importância do território para o desenvolvimento rural. Discute um novo enfoque do desenvolvimento rural apoiando-se no alargamento da abrangência espacial, ocupacional e setorial do rural. Indica a necessidade de consolidar o deslocamento da idéia de região para a de território resgatando tanto as implicações como as resistências a esta operação efetuada pela geografia de hoje. Critica estudiosos, organismos internacionais e governos que fazem uso normativo e operacional da abordagem territorial. $\mathrm{O}$ autor procura um outro enfoque para o desenvolvimento rural, baseado no conceito de território. Sua abordagem é a que mais se aproxima do olhar geográfico e tem sido de grande valia para nosso trabalho.

Embora fortemente influenciados pela tese da urbanização da sociedade - do rural (ideológica,cultural, extensiva), integrada à lógica capitalista, numa aproximação com Léfèbvre, reconhecemos que os autores referidos na segunda "vertente" analítica têm razão ao chamar atenção para a diversidade desse processo e para a reapropriação de elementos da cultura local pelo urbano.

As duas abordagens teóricas apresentam análises parciais pois, cada uma, isoladamente, não contempla a complexidade que marca o rural de hoje, participante das múltiplas escalas da ação social. É por isso que tentaremos apresentar algumas idéias integradoras, em que os, aparentemente contraditórios, dialoguem, bem à maneira de Morin. Território e escala serão ferramentas preciosas para re-apresentar a multiplicidade das interações urbano-rurais que marcam as transformações pelas quais passa o rural nos dias atuais. A essas transformações denominamos de "urbanidades no rural", que podem, no nosso entender, constituir uma terceira abordagem analítica, integrando algumas das formulações apresentadas nas "vertentes" definidas. Para um grupo de autores a análise centra-se na cidade e no urbano, enquanto para outros, o foco, desloca-se para o campo e para as especificidades do rural. Para nós, desenham-se múltiplas espacialidades/territorialidades (híbridas de urbano e rural, numa integração multiescalar), que marcam o momento atual de (re)significação do rural e da natureza.

\section{Urbanidades no rural: buscando a multidimensionalidade na complexidade do rural.}

A ressignificação do rural, através da idéia de "urbanidades no rural" inclui uma série de representações que re-apresentam este espaço como um "outro rural". Este, concebido, primordialmente, na cidade, 
como uma nova mercadoria, comporta a face "natural" da natureza e porta uma virtualidade, que se torna real. Virtual e real se confundem nas recriações que as novas representações do rural carregam. Essa "virtualidade" integra aspectos da virtualidade lefevriana, do vir-a-ser da sociedade urbana, mas realizase, concretamente, na hibridez que marca o rural, em geral, e o fluminense em particular. $\mathrm{O}$ valor de uso está submetido ao valor de troca como essência da reprodução do capital numa sociedade de consumo. O rural se vê consumido como virtual antes mesmo de se tornar mercadoria incorporado aos diferentes discursos políticos (mas, também, midiáticos) como referência cultural, para a sociedade como um todo.

Por outro lado, percebe-se que a ressignificação do rural não é fruto apenas de criações urbanas, mas também das leituras particulares por parte dos habitantes das áreas rurais, conformando um caráter híbrido ao território e às identidades criadas com componentes "rurais" e "urbanos", usados, estrategicamente, como discursos e reivindicações predominantes, de acordo com a situação, conforme pudemos constatar nas entrevistas efetuadas, em que situações de inferiorização (frente aos urbanos) e de reivindicação de direitos conviviam nos relatos. Mais uma vez ficou evidente o caráter híbrido das identidades territoriais construídas, principalmente naquelas áreas de maior adensamento de "urbanidades" - Região Serrana e Vetores litorâneos.

Mesmo dando destaque às dimensões cultural e simbólica, não se pode deixar de lembrar que o que se observa é uma permanente recriação do capitalismo, nunca restrito à dimensão econômica, mas contemplando as múltiplas dimensões das relações sociais. Uma espécie de volta sobre si mesmo, revalorizando espaços que já estavam dentro da lógica capitalista e, desigualmente, voltam a se ver como mercadorias valiosas num movimento de tendências contraditórias para a igualização e para a diferenciação, como nos elucidou Smith (1988, p. 149) ao falar da produção capitalista do espaço.

Mas enunciar que o capitalismo se desenvolve desigualmente pode dizer muito pouco a respeito da escala em que se dá tal desenvolvimento desigual. Por isso é necessária uma busca da compreensão desse processo a partir de realidades concretas e em escalas definidas, como em nossa pesquisa sobre o rural no estado do Rio de Janeiro.

Ao falar de ressignificação do rural e de recriação pelo capitalismo queremos refletir sobre as múltiplas formas de reconstrução desse espaço em termos materiais e imateriais/simbólicos em que fixos da fase anterior são destruídos ou refuncionalizados para viabilizar reterritorializações permanentemente refeitas.

Discutindo o papel do território como locus do exercício da política e do poder, Moreira (2004, p. 2) esclarece que as disputas territoriais que se expressam na dinâmica territorial fluminense carregam interesses rurais e urbanos, locais, nacionais e globais, agrícolas e industriais, bem como aqueles ligados à cultura e ao turismo. Nessas disputas diversas instituições projetam seus interesses no território, como o IBAMA, o INCRA, as prefeituras, proprietários e especuladores de terras, empresários do agronegócio e do turismo, agricultores familiares (proprietários e parceiros) e assentados, movimentos ambientalistas e dos que lutam pela reforma agrária, proprietários de sítios e de condomínios de segunda residência, todos vivenciando assimetricamente o exercício do poder, numa busca de manutenção de hegemonias e de construção de contra-hegemonias o que provoca constantes conflitos.

Em nossa pesquisa temos tentado ultrapassar o corte tradicional rural/urbano, e tomar por base as "novas territorialidades", com usos estabelecidos pela ampla participação dos interessados - habitantes das áreas de estudo. A sociedade local pode (e deve) exercer, permanentemente, um diálogo com o território, e que esse diálogo inclui as coisas naturais e artificiais, a herança social e a sociedade em seu movimento atual, como preconiza Santos (2000, p. 26).

Esse diálogo assenta-se em intrincada gama de elementos que marcam um dado local. Podem ser de 
natureza interna e atrair e interagir com os fatores externos, numa combinação transescalar que caracteriza cada lugar, de maneira singular. Tudo isto se processa em um movimento histórico que evidencia o dinamismo do espaço geográfico.

As particularidades e singularidades se reapresentam recentemente, principalmente, com a abertura da malha rodoviária que integrou quase todo o rural fluminense a uma lógica sócio-espacial supra-local, isto é, os fatores externos, de origem predominantemente urbana, passaram a ser fundamentais na definição dos rumos tomados pelos lugares rurais. O dinamismo da expansão das urbanidades (turismo, veraneio, da especulação imobiliária, da estruturação do mercado de trabalho e a vinda de empreendimentos e pessoas de fora das localidades para nelas trabalharem ou residirem, colocam desafios crescentes, que afetam a identidade territorial de seus habitantes.

Qualquer ator social procura desenvolver condições de controlar pessoas e objetos localizados em seu território, para com isso, efetivar projetos políticos, econômicos ou culturais. O território torna-se um importante instrumento da existência e reprodução do ator social que o criou e/ou o controla.

Na busca de uma definição mais integradora para território, Haesbaert (1997, p. 42), recorre a diversos autores consagrados, e assim escreve:

O território envolve sempre, ao mesmo tempo mas em diferentes graus de correspondência e intensidade, uma dimensão simbólica, cultural, através de uma identidade territorial atribuída pelos grupos sociais, como forma de "controle simbólico" sobre o espaço onde vivem (sendo também, portanto, uma forma de apropriação), e uma dimensão mais concreta, de caráter político-disciplinar: a apropriação e ordenação do espaço como forma de domínio e disciplinarização dos indivíduos.

Aí, o autor, nos remete às dimensões variadas que compõem aquela noção. Dentre elas, selecionamos duas que nos pareceram mais significativas para um estudo sobre a identidade do rural. A primeira seria a simbólico-cultural, em que o território é visto, sobretudo, como produto da apropriação/valorização simbólica de um grupo sobre seu espaço e onde os geo-símbolos, que definem uma paisagem cultural, marcam a inscrição da cultura de um grupo sobre seu espaço. A segunda dimensão é a jurídico-política, bastante difundida, onde o território é visto como um espaço delimitado e controlado, através do qual se exerce um determinado poder, na maioria das vezes visto como o poder político do Estado. (Haesbaert, 2001, p. 1770) Nos espaços rurais, estas duas dimensões, estão em constante conflito, manifestado na permanente intenção das prefeituras de "urbanizar" as áreas tidas como rurais, na perspectiva de maior arrecadação de IPTU.

Não podemos deixar de mencionar as dimensões econômica (que enfatiza as relações produtivas no embate entre classes sociais e na relação capital-trabalho, em sua espacialidade) e a que se baseia nas relações sociedade-natureza (no que se refere ao desigual usufruto dos recursos naturais, mas, também numa série de símbolos e signos que marcam tal relação). Estas últimas merecem referência pelo fato de haver, nas pequenas localidades e nos territórios rurais, uma preocupação recente com o ambiente natural, num discurso ecologista de origem urbana (mas com intensas repercussões nas áreas rurais) a respeito da natureza "natural", que vem sendo crescentemente apropriado como elemento de revalorização do rural/local.

O controle de um espaço (feito território), privilegiando um uso mais funcional ou mais simbólico, pelos atores que promovem tal uso, como vimos anteriormente, leva-nos a analisar tal vivência pelo viés das múltiplas territorialidades, seguindo Haesbaert (2004 e 2005). Tais atores podem vivenciar, embora de forma desigual, concomitantemente uma enorme gama de territórios. Alguns grupos, os mais privilegiados, usufruem de uma multiplicidade inédita de territórios, seja no sentido da sua sobreposição num mesmo 
local, seja de sua conexão em rede por vários pontos do mundo. É importante ressaltar, para não deturpar o pensamento do autor supracitado, que não se trata simplesmente da imbricação ou da justaposição de múltiplos territórios que, mesmo recombinados, mantêm sua individualidade.

As inúmeras territorialidades experimentadas por um usineiro do Norte-Fluminense, com casa, empresa e terras na região, mas com residências (secundárias ou não) em Ipanema e em Paris, contrasta com a quase mono-territorialidade do cortador de cana da baixada campista ou do meeiro da Região Serrana, em suas vivências cotidianas limitadas. Nas localidades em que a presença de turistas (muitas vezes estrangeiros) e/ou veranistas é mais significativa, esse contraste é ainda maior, por conta do convívio social mais intenso entre esses atores. As alterações sofridas na territorialidade cotidiana de um pescador de Mangaratiba (num dos vetores litorâneos) são marcantes ao mudar seu calendário de pesca, por conta da época de turismo, ao alugar seu quintal para campistas ou sua casa por temporada, por exemplo. É preciso referir a vivência virtual das territorialidades "carregadas" pelos turistas, nos relatos efetuados por eles, nos hábitos diversos, tão contrastantes com os dos "locais". O que se deseja reforçar é que o capitalismo tem encontrado novas forças de se transfigurar em múltiplas novas mercadorias - rural e natureza, em nossa exemplificação - e em criar outras formas de desigualização social e espacial, em que a possibilidade (ou não) de experimentar as múltiplas territorialidades se coloca como centro dessa desigualização.

Outro aspecto que deve ser enfatizado é a vivência multiescalar e transescalar dos territórios. As múltiplas territorialidades são vividas em múltiplas escalas (mais amplas ou mais restritas). Distinguimos (precariamente) esses dois termos pensando relacionar a multiescalaridade à capacidade de vivenciar diversas escalas sincrônica ou diacronicamente, enquanto a transescalaridade poderia relacionar-se à capacidade de "transitar" indiferenciadamente pelas diversas escalas. O primeiro termo poderia estar mais ligado aos indivíduos, socialmente diferenciados; o segundo termo poderia estar mais ligado às empresas e ao capital financeiro, como mercadoria maior da contemporaneidade.

Não se pode pensar o urbano e o rural, o local e o global, como polaridades, mas como interações assimétricas que não devem silenciar as intensas disputas sócio-espaciais que obrigam a permanentes reconfigurações das escalas de ação. O território "urbanizado", numa escala mais ampla, em geral, está relacionado a espaços de dominação que impõem suas representações. Na escala local, essas representações também se fazem presentes nas relações assimétricas que aí, também, vigoram. Entretanto, é aí, que se processam os movimentos de resistência e de criação de alternativas e/ou estratégias de sobrevivência que podem se manifestar como releituras daqueles movimentos mais gerais que marcam o espaço contemporâneo. O local e o geral/global aparecem integrados pelas escalas da ação.

É nessa perspectiva transescalar e multiterrorial que compreendemos a interação urbano-rural, a partir da idéia de urbanidades no rural. Já em Rua (2002a, p. 39), afirmamos que o movimento de difusão de urbanidades no rural se daria de maneira diversificada quando escrevemos que:

Tentamos trabalhar com uma visão de urbanização que ultrapasse a dimensão física do processo (expansão da área construída) e incorpore as dimensões ideológica e cultural. Valores, atitudes e padrões de comportamento são modificados, principalmente, a partir das cidades, e espalham-se pelo território num movimento, simultaneamente, extensivo e intensivo como uma nova fronteira para o capitalismo onde se combinam, desigualmente, em cada localidade, o rural e o urbano (RUA, 2002a, p. 39).

Procura-se apresentar/estudar o movimento de expansão das urbanidades ${ }^{9}$ nas áreas rurais, compreendendo a presença do "urbano" lefevriano nessas áreas como manifestação do processo geral de transformações, pelo qual passa o espaço, sem que isso se perceba como destruição do rural e sim como 
difusão de "urbanidades no rural" integrando-se a "novas ruralidades" preconizadas por Maria José Carneiro, numa gestação de um espaço híbrido produto de novas relações que não podem ser explicadas apenas pelas concepções tradicionais de urbano e rural. A idéia de hibridez tenta ultrapassar a antinomia campo-cidade e reconhecer um papel para o rural em que a possibilidade da existência da multiplicidade abra caminho para novas interações que ainda estão por ser realizadas. A percepção de que no rural se vivenciam desigualmente (tal como no urbano) múltiplas territorialidades e trans-múltiplas escalaridades, ainda por realizar, auxilia nossa análise.

As "urbanidades no rural" seriam todas as manifestações do urbano em áreas rurais sem que se trate esses espaços formalmente como urbanos. Não se pretende criar conceitos novos que obstaculizem, mais ainda, a discussão, mas indicar: que a idéia de urbanização rural dificulta a compreensão dos processos em curso pelo caráter homogeneizador e simplificador que carrega; que a urbanização, difusa, ideológica/ cultural, como já foi referido, dificilmente pode ser mensurada. A idéia de "novas ruralidades" parecenos enfatizar por demais a força do rural diante do urbano que, sem dúvida, comanda o processo de reestruturação espacial no mundo contemporâneo. Deve-se abrir possibilidades outras para a construção de identidades locais que se territorializam.

Por outro lado, a idéia de "inovações transformadoras", que utilizaremos, ao longo deste trabalho, não deve ser entendida como algo semelhante à difusão de inovações da ciência regional ${ }^{10}$, onde se desenvolvia uma espécie de troca desigual entre cidade e campo, em que este se apresentava como um receptor passivo das inovações, sempre urbanas, e devolvia os "frutos" do investimento efetuado pelos pólos urbanos.

As inovações transformadoras a que nos referimos constituem "criatividades" locais, que às vezes nem são de origem rural e tornam-se elementos catalizadores de "urbanidades". Por exemplo: um grupo de moradores (às vezes, associações), motivado por uma campanha ecológica de uma escola da cidade, participa da limpeza de um rio e demanda uma rede de esgotamento sanitário. Nesse movimento surgem novas demandas e soluções para compras coletivas de insumos e formas comuns de escoamento da produção. Aí teríamos exemplos de inovações transformadoras de origem urbana e de origem rural. Todas vão se constituir em "urbanidades".

Ao utilizarmos a expressão "Inovações tranformadoras", voltamos a lembrar, pretendemos distinguirnos daquelas formulações positivistas e neopositivistas, unilaterais, e que centram as inovações em pólos. Ocidente, grandes cidades, cidades, são vistas, apenas, como escalas de uma hierarquia de pólos criadores de inovações onde não cabem os não-ocidentais, os não-metropolitanos, os não-urbanos.

O urbano de Léfèbvre não é resultado da ação de uma cidade específica sobre o espaço - 'é um projeto societário, é um vir-a-ser que se constitui em um espaço-tempo renovado; topologia distinta do espaço-tempo agrário (cíclico, que justapõe as particularidades locais). Contrapõe-se, como diz o autor, ao espaço-tempo industrial, que ainda predomina, e que leva à homogeneidade. $\mathrm{O}$ urbano permite, em escalas diversas, a heterogeneidade - a heterotopia em que os lugares são relativos uns aos outros no conjunto urbano (LÉFÈBVRE, 1999, p. 45).

Portanto parece-nos não haver contradição entre essa visão do urbano como projeto (em que cada lugar e cada momento têm existência num conjunto, nele se dintinguindo) ou como virtual e as escalas locais de análise, por isso nossa hesitação em arrolar o autor numa vertente analítica específica, já que suas reflexões nos permitem integrar as escalas mais amplas às escalas mais locais.

$\mathrm{Na}$ escala mais ampla projeta-se aquilo que denominamos, neste trabalho, urbanização ideológica (difusa, comportamental ...), com tudo de impreciso que essa terminologia acarreta. Na escala local desenrola-se um movimento mais concreto, mensurável em certos aspectos. É aí que se percebe o caráter 
híbrido do território. Um rural que interage com o urbano, sem deixar de ser rural; transformado, não extinto. A hibridez permanente evidencia a "criação local", isto é, a capacidade dos atores locais de, influenciados pelo externo, de escala mais ampla, desenvolverem leituras particulares dessa influência e produzirem territorialidades particulares. Essas territorialidades, diferenciadamente vividas, podem traduzir-se em múltiplas territorialidades para alguns, e reduzida capacidade de experimentá-las, para a maioria, tornando-se, assim, mais um elemento desigualizador.

A interação entre a escala mais restrita, do lugar, e a mais ampla, da sociedade urbana, se dá, também, de maneira desigual e com caráter desigualizador. A possibilidade de vivenciar diversas escalas e de "transitar" entre elas, desconhecendo-lhes os limites, é desfrutada por poucos. A maioria das pessoas de um dado local, vive e experimenta escalas muito limitadas, em sua capacidade de ação, ao mesmo tempo em que interage em territorialidades restritas.

Fica claro, assim, que a análise balizada por recortes administrativos torna-se bem menos significativa do que as abordagens normativas insistem em apresentar. A escala da ação torna-se, cada vez mais, um elemento definidor das interações espaciais, em nosso caso, das interações do rural com o urbano.

O desafio, colocado pelo empírico, está em como operacionalizar tal abordagem, escapando dos limites político-administrativos e dos dados estatísticos, sem, entretanto, desconhecer-lhes a capacidade, embora limitada, de atuarem como "indicadores" da existência dos fenômenos, não de os definirem.

\section{Uma necessária aproximação com a empiria. Recomeçando.}

Essa discussão das definições e das relações entre rural e urbano, bem como dos novos qualificativos desse rural, é importante pois permite perceber melhor a complexidade da sociedade brasileira e de suas representações espaciais, dominantes até aqui, e do apoio a lutas pela democratização dessa sociedade em que propostas de novos espaços de representação possam ser transformadas em outras representações espaciais.

É Moreira (2003, p. 133) quem, mais uma vez, nos recorda que

Em cada momento histórico as forças sociais que exerceram a hegemonia tiveram uma visão de si mesmo, da nação, do lugar dessa nação no concerto internacional,bem como do lugar do rural em seus projetos de nação. Tais forças projetaram políticas agrícola e agrária bem como projetaram suas instituições rurais.

Isto nos lembra como é necessária uma Reforma Agrária e a democratização do acesso à terra e à renda da terra - não adianta ter terra se não houver condições de reter a renda da terra nas mãos dos agricultores. A terra própria, o acesso à renda da terra, a possibilidade de viver bem da agricultura, ou no meio rural ainda não se apresentam como realidade para boa parte da população rural brasileira.

Para nós, o rural tem de ser percebido como um espaço incorporado/incorporador ao/do processo geral de urbanização; integrado ao urbano mas guardando algumas especificidades (já que o processo de transformação ocorre de maneira muito diversa de umas localidades em relação a outras), que são "oferecidas", "descobertas", "exploradas" como "atrações locais" (onde as identidades diferenciadoras são enfatizadas). Por outro lado, tem a sua participação intensificada em circuitos e redes sobre os quais não tem poder de decisão (circuitos de circulação, redes logísticas e informacionais). Novas atividades e funções do rural (incluindo a função de residência - primeira ou segunda - para populações urbanas), além do importante papel da aposentadoria rural ou o trabalho a domicílio, por exemplo, marcam estas novas formas de integração rural-urbana, com distinções cada vez mais difíceis de serem estabelecidas, entre essas duas espacialidades. Os próprios assentamentos rurais, compreendidos como importantes 
inovações transformadoras, produto de mobilizações diversas (com participantes de origem rural e urbana), ao fornecerem "experiências urbanas" durante a luta pela terra, podem ser percebidos como mais um deflagrador de "urbanidades".

Outra inovação transformadora digna de registro no estado do Rio de Janeiro, responsável por uma intensificação da urbanização e por gerar diversas "urbanidades", foi a onda emancipatória que varreu o estado no final dos anos oitenta, ao longo dos anos noventa e prosseguindo, com menor intensidade, nos primeiros anos desta década, em decorrência da Constituição de 1988, que estabeleceu a transferência de recursos para os municípios em nome da descentralização. Tal onda emancipatória tem sido alimentada, também, pela possibilidade de ter acesso aos "royalties" pagos pela Petrobrás. Como são verbas que estiveram comprometidas com investimentos em algumas rubricas básicas (hoje há mais liberdade para o uso de tais recursos), acabaram por se constituir num outro acelerador de "urbanidades", ao incentivar a construção e melhoria da rede viária, da rede de postos de saúde e da rede escolar, dentre outras inovações. Os municípios correspondem a forças políticas que expressam novos pactos entre os poderes locais e as instâncias superiores da ordem federativa. Os 28 municípios, quase um terço do total criado no estado do Rio de Janeiro, naquele período, alteraram, profundamente, o mercado de trabalho ao ampliarem o setor terciário da economia e criarem, indiretamente, diversas "urbanidades no rural" que aceleram a expansão da urbanização.

Essa fusão de fundamentações sintetizadas na idéia de "urbanidades" não significa uma indecisão teórica ou de um ecletismo conciliador. Ao contrário, busca-se um pluralismo imposto pela realidade multifacetada em que se manifesta tamanha diversidade que nenhuma das abordagens teóricas apresentadas parece ser suficiente para abranger tal diversidade.

Em algumas áreas da Região Serrana ocorre uma verdadeira destruição do rural, motivada por uma avassaladora urbanização centrada em atividades de turismo, veraneio, industrialização, construção civil, que retiram, permanentemente, das atividades agrícolas e das áreas rurais numerosas famílias. Os dois tipos de urbanização (física e ideológica) se superpõem e parecem dar razão aos autores da linha interpretativa mais "clássica". Este fenômeno, se bem que comum, em alguma intensidade, a todo o espaço fluminense, é mais perceptível em algumas áreas da Região Serrana, principalmente ao longo da rodovia Teresópolis - Nova Friburgo e em setores de São Pedro da Serra, neste último município, por exemplo.

Em outras áreas, da mesma região, onde aparece com destaque uma pluriatividade integrada ao turismo, ao veraneio, e ao trabalho doméstico para a indústria. Várias áreas de Nova Friburgo, Duas Barras e Bom Jardim integram-se bem à idéia contida no conceito de "novo rural" como enunciado por Graziano da Silva..

Finalmente, ainda na Região Serrana e na maior parte do Norte Fluminense (Quissamã, como exemplo) percebe-se, claramente, a presença de "urbanidades" como marca da urbanização, num rural modificado, mas sem perder suas especificidades, parecendo dar razão a Maria José Carneiro.

Em nossa busca de aceitar os desafios postos pela tensão teoria-empiria temos nos apoiado nos métodos desenvolvidos por Morin $(1999,2001,2002)$ e de Léfèbvre (1981). Procuramos incorporar, alguns dos ensinamentos desses autores, embora com resultados muito parciais, ainda marcados pela retórica do pensar como fazer e sem ter clareza de como integrar a praxis com o produto obtido.

Aos dados estatísticos obtidos contrapomos dados qualitativos resultantes de inúmeros trabalhos de campo, percorrendo, praticamente, todo o interior do estado do Rio de Janeiro, que serviram para a elaboração de um mapa já apresentado em Rua (2002b) onde se definem os eixos de maior adensamento de urbanidades - trabalho inicial que deve ser retomado e acompanhado permanentemente.

Nesses eixos pode ser observada uma sensível transformação no padrão da renda fundiária em que se 
misturam duas lógicas do uso da terra - a rural e a urbana. Embora haja um uso predominante (espacial, mas não em termos de rendimentos obtidos) voltado para a agricultura e para a pecuária, destacam-se outros usos integrados à lógica urbana de renda territorial, incluindo as formas especulativas em terrenos subaproveitados, que, posteriormente, poderão ser transformados em loteamentos ou condomínios de luxo. Esta é, certamente, uma das mais freqüentes manifestações de "urbanidades" no rural fluminense, principalmente nos eixos da Região Serrana e dos dois vetores litorâneos.

Ao nos determos no método investigativo, remetemo-nos a Morin (1967, p. 394), quando escreve que a reflexão e a prospecção não podem ser efetuadas em tempos separados e que o corpo das hipóteses não pode ser estabelecido uma vez por todas baseado numa pré-pesquisa mas, ao contrário deve poder se desenvolver e se modificar com o desenvolvimento da pesquisa, devendo, ainda, por seu lado poder modificar o curso do trabalho e das técnicas de investigação. Tenta-se buscar o rigor científico, não na rigidez, mas numa estratégia de adaptação permanente.

A pesquisa não pode impedir a retroação sobre o real, a correção, a inovação. Na pesquisa sobre as urbanidades no rural fluminense usam-se questionários (embora como instrumento menor de verificação), dados censitários e outras fontes primárias, sempre relativizadas, mas preferiu-se a entrevista aberta e as conversas informais, onde se procurou descobrir os fatos significativos para a investigação e a participação em atividades locais (praxis social).

Com isso, em nosso estudo, procura-se favorecer a emergência dos dados concretos (aqueles que foram sendo descobertos ao longo do trabalho); buscou-se explicitar as diversas dimensões dos fenômenos estudados e, para isso, apelou-se a diversos tipos de abordagem; incorporou-se a correção e a verificação ao longo do desenvolvimento do pensamento interpretativo.

O mais importante, entretanto, tem sido a longa observação (mais de sete anos) voltada tanto para a vida social, dos lugares mais visitados como individual e acompanhada pelas outras formas de investigação, mas permanecendo autônoma. O estoque constituído de anotações e observações se revela, à medida em que o terreno se torna inteligível, um viveiro de dados, onde o detalhe se torna cada vez mais significativo.

A nossa formação nos atraiu para a especial atenção à práxis social, quer dizer à realidade e à ação dos grupos sociais. A ação é não somente o revelador de realidades que raramente afloram pela palavra, mas é a própria realidade da vida social. A ação e a nossa participação na ação nos chama atenção para a relação (de interesse mútuo) entre o investigador e os movimentos sociais. O investigador pode contribuir para a construção de territorializações mais democráticas e favorecer processos de busca por contra-espaços, como nos lembra Léfèbvre (1986), ao abrir diálogo com os diferentes agentes sociais e fortalecer as contra-correntes apresentadas por Morin.

Assim, deve-se tentar analisar a importância dos lugares na organização dos diversos movimentos sociais como bases onde se manifestam as múltiplas relações de poder em formas de dominação ou de resistência. O espaço, transformado em território, pelas práticas espaciais de seus habitantes, não é apenas domínio de quem o administra, ordena e controla utilizando representações do espaço mas, também, da interação dinâmica e fluida entre o local e o global, o individual e o coletivo, o privado e o público e entre a resistência e a dominação, Ele está em permanente devir, como nos lembrou Massey (1999, p. 281).

Esta discussão em torno das definições de urbano e rural é importante pois implica em diferentes projetos de territorialidades (cada qual com distintas propostas políticas) para os atores envolvidos. As ações interventivas, incluindo a necessária reforma agrária, têm de levar em consideração o processo de urbanização/difusão de urbanidades em áreas rurais e as transformações econômicas, culturais, sociais e políticas advindas desse processo de alteração do significado de "rural", sem a inevitável homogeneização rural/urbana como preconizada por muitos autores da abordagem "clássica". 
O que se pretendeu demonstrar foi que há uma espacialidade integrada a um "urbano" difundido por todo o território; que há um rural, com leituras particulares (criações locais) desse movimento mais amplo, que interage com aquele "urbano"; que essas interações transformam os espaços rurais em territórios híbridos (resultado dessas interações) nos quais se dão variadas formas de apropriação e dominação; que as marcas dessa hibridez são as "urbanidades no rural", integradoras das múltiplas escalas que a ação política exige. Assim, deve-se perceber a nossa proposta como capturadora de elementos das duas "vertentes" analíticas, mas dando destaque à escala da ação, esta sim, necessariamente integradora.

As manifestações, fruto da expansão da urbanização da sociedade para áreas rurais, inseridas em processos mais amplos de re-estruturação espacial, coexistem com aquelas que resultam de movimentos de afirmação do local não como polarizações excludentes mas como pares dialéticos interagentes. Os processos gerais não implicam, necessariamente, em homogeneização já que ela é interpretada de diferentes maneiras por diferentes grupos e em diferentes locais dentro de uma infinita gama de "imaginações geográficas" (RUA, 2000, p. 157).

No dizer de Santos $(1996,272)$

A ordem global busca impor, a todos os lugares, uma única racionalidade. E os lugares respondem ao Mundo segundo os modos de sua própria racionalidade (...). A ordem global funda as escalas superiores ou externas à escala do cotidiano. Seus parâmetros são a razão técnica e operacional, o cálculo de função, a linguagem matemática. A ordem local funda a escala do cotidiano, e seus parâmetros são a co-presença, a vizinhança, a intimidade, a emoção a cooperação e a socialização com base na contigüidade.

Ao estudar o urbano e as urbanidades (e suas manifestações), nas áreas escolhidas, tentamos utilizar escalas diversas que vão dos processos mais gerais até a materialização desses processos em escalas mais locais com a deliberada intenção de identificar as intermediações entre as partes e o todo e permitindo a incorporação das observações empíricas na análise. Na escala mais geral perceberíamos o sentido do desenvolvimento brasileiro - autoritário, conservador e urbano-cêntrico, procurando impor representações do espaço homogeneizadoras e reprodutoras do padrão hegemônico. Esse projeto de igualização provoca, contraditoriamente uma desigualização, em escalas menores, que se ligam a movimentos de resistência àquela homogeneização, embora não sejam exclusivos dela. As necessárias. multiescalaridade e transescalaridade resgatariam a ação integrada em nível nacional, regional, local e, como utopia no momento, mesmo a escala global.

O desenvolvimento compreendido como desigual e combinado, mesmo numa era de globalização, apresenta inúmeras possibilidades com a perspectiva da continuidade da geração dessas desigualdades e diferenças culturais e de visões locais ou globais levando a sua continuidade através do poder da diversidade reproduzida com base em relações globais. Assim as relações sociais e políticas locais não são apenas produto da maneira como os processos globais funcionam mas ajudam a influenciar o contexto global. Deste jogo até mesmo as localidades pequenas participam através da influência política e do marketing do local que se generaliza.

Por outro lado tem de ser observado que a revalorização do local/rural se, nas sociedades consolidadas como as européias, pode levar a uma lógica de co-gestão participativa ou a uma construção de identidades, em sociedades como a brasileira, marcada, atualmente, por uma descentralização tributária e administrativa, se pode, em alguns lugares, consolidar aqueles processos, em outros pode levar ao fortalecimento das oligarquias tradicionais que, muitas vezes, nem foram alijadas do poder como ocorre, em geral, no Brasil..

O que pretendemos, ao participar deste debate, é lembrar o quanto nós, geógrafos, podemos oferecer 
para seu enriquecimento e, ao mesmo tempo, reforçar a idéia de diversidade territorial, nas áreas rurais, fruto de desigualdades e diferenciações que não cessam de se manifestar.

É necessário fazer mais estudos locais para detectar essa diversidade e perceber como os processos globais, ligados à lógica do desenvolvimento do capitalismo, (que nunca pode ser entendido apenas como desenvolvimento econômico) se manifestam concretamente nas múltiplas interações do global com os locais.

Tal multiplicidade nos lembra o movimento dialético do todo social e como esse movimento é apreendido em um ponto geográfico, um lugar, ao mudar permanentemente a sua significação, como sempre nos lembrou Milton Santos.

\section{Notas}

(1) Este trabalho é efetuado no Núcleo de Estudos da Geografia Fluminense (NEGEF) do Departamento de Geografia da UERJ, do qual fazem parte, além deste autor, os professores Gláucio José Marafon e Miguel Ângelo Ribeiro. O núcleo já apresenta significativa produção geográfica sobre o território fluminense e desenvolve relevantes atividades de iniciação científica com os numerosos bolsistas que dele também fazem parte.

(2) Estas reflexões vêm fundamentalmente, do diálogo travado com esse autor, quando de sua defesa de dissertação de mestrado, de contatos posteriores e da leitura de algumas obras de Marx, particularmente Marx, Karl. e Engels, Friedrich A Ideologia Alemã. São Paulo: Martins Fontes, 1998.

(3) Essa tradição, tão fortemente enraizada, vem de Sorokin, Zimmerman e Galpin (1986)[1930] e de Wirth (1976) [1938].

(4) Para uma análise mais completa, seria necessário referendar, também, Corêa, Roberto Lobato. A Rede Urbana. São Paulo: Atica. 1989, onde o autor analisa as relações cidade-campo através das migrações, da comercialização da produção rural, da drenagem da renda fundiária, da difusão de valores e ideais. Como não se ocupa explicitamente da temática em tela, recomendamos sua leitura, mas não o integramos ao corpo do trabalho.

(5) Blume (2004), destaca Veiga e Abramovay) numa outra linha à qual denomina territorial, em que os aspectos normativos sobre as definições de urbano e rural promovidas por instituições governamentais e de pesquisa, teriam destaque.

(6) Interessante discussão a respeito dos critérios utilizados pela OCDE, para definir rural e urbano, é travada por Blume (2004, p. 88) em que o autor, ao preparar as bases de aplicação de tais critérios ao Rio Grande do Sul, escreve: "A OCDE, preocupada em proporcionar um recorte diferenciado para o estudo do rural nos países membros, desenvolveu uma metodologia baseada em elementos territoriais para orientar um novo recorte normativo. Para operacionalizar a abordagem territorial foram utilizados como parâmetros indicadores demográficos. A partir do resultado desserecorte territorial, foram efetivadas as leituras para as dinâmicas territoriais urbano-rurais nestes países" (BLUME, 2004, p. 87)..

(7) Ana Fani Alessandri Carlos, em CARLOS, Ana Fani alessandri. O Espaço Urbano, novos escritos sobre a cidade. São Paulo: Contexto, 2004, faz vigorosa crítica à obra Cidades Imaginárias de José Eli da Veiga. Essa crítica alertou-nos para diversos aspectos que havíamos negligenciado.

(8) Transitar indiferenciadamente quer dizer "desconhecer" propositadamente os limites das escalas da ação, tal a força dessa ação. Seria um pouco semelhante à distinção que Haesbaert (2005) procura fazer entre multiterritorialidade e múltiplos territórios.

(9) Lembramos, que para nós, o termo "urbanidades" não tem o mesmo sentido de "urbanidade" usado por Marx, por Lefèbvre ou por Levy (ver bibliografia), todos referindo-se a qualidades do urbano e, quase sempre, das cidades. Urbanidades no rural foi inspirado na obra de Poulle e Gorgeu (1997), sem respeito à sua concepção original - urbanité rurale. 
(10) A difusão de inovações (e do difusionismo), tão cara à Geografia e às ciências espaciais, em sua tradição que vem da Antropologia Cultural do séc XIX, insere-se na perspectiva de expansão da "matriz racional", do progresso e do desenvolvimento, ao colocar o "Ocidente" como o inovador, o criador de progresso e, mais tarde, de desenvolvimento. Muitas críticas vêm sendo endereçadas ao difusionismo e à teoria da difusão de inovações. Santos (1978, p. 46), por exemplo, ao criticá-la, lembra, citando Hurst, que a simulação da difusão de inovações através do espaço, sem a compreensão de por que algumas pessoas aceitam a inovação, e outras não, levaria à descrição de padrões complexos sem a necessária compreensão dos processos que lhes dão suporte. Na mesma página, Santos lembra uma advertência de Hagerstrand que diz: "a ordem espacial na adoção das inovações é muitas vezes tão chocante que ela constitui uma tentação para que tentemos criar modelos teóricos que simulem os processos e façam com que se obtenham certas precisões". A inovação pode ser uma técnica, um produto, uma prática ou mesmo uma idéia adotadas com maior ou menor receptividade.

\section{Referências}

ABRAMOVAY, Ricardo. Funções e Medidas da Ruralidade no Desenvolvimento Contemporâneo. Texto para discussão n. 702. IPEA. Jan. 2000.

ABRAMOVAY, Ricardo. Conselhos além dos limites. Estudos Avançados. São Paulo: USP, v. 15, n. 43, p. 121 140. set-dez. 2001.

BLUME, Roni. Território e Ruralidade: a desmistificação do fim do rural. Dissertação de mestrado apresentada ao Programa de Pós-graduação em desenvolvimento Rural. PGDR. UFRGS. 2004.

BOTELHO, Maurílio Lima. A relação campo-cidade em Léfèbvre e Debord: a revolução urbana no marxismo tardio. Mimeografado. 2005(a).

A relação campo-cidade em O Capital de Marx: um estudo dialético. Dissertação de mestrado apresentada ao Curso de Pós-graduação em Desenvolvimento, Agricultura e sociedade. CPDA, UFRRJ. 2005(b).

CARLOS, Ana Fani Alessandri. O Espaço Urbano, novos escritos sobre a cidade. São Paulo: Contexto, 2004,

CARNEIRO, Maria José. Ruralidade: novas identidades em construção. Estudos Sociedade e Agricultura, Rio de Janeiro. N. 11, p. 53-75. out. 1998.

CORRÊA, Roberto Lobato. A Rede Urbana. São Paulo: Atica. 1989.

GRAZIANO DA SILVA, José. O Novo Rural Brasileiro, In: Nova Economia. Belo Horizonte. 1997.

. O Novo Rural Brasileiro. 2. ed. Campinas: UNICAMP/IE. 1999.

Políticas Não Agrícolas Para o Novo Rural Brasileiro. Anais do $36^{\circ}$ Congresso Brasileiro de Economia

e Sociologia Rural, p. 117-142. Poços de Caldas. 1998.

HAESBAERT, Rogério. Da desterritorialização à multiterritorialidade. X Encontro de Geógrafos da América Latina. São Paulo: USP, 2005.

Da Desterritorialização à Multiterritorialidade. In: ENCONTRO NACIONAL DA ANPUR. IX, 2001. Rio de Janeiro: ANPUR, 2001, p. 1769-1777.

Des-territorialização e Identidade a rede "gaúcha" no Nordeste. Niterói: EDUFF, 1997. 293p.

O Mito da Desterritorialização: do "fim dos territórios" à multiterritorialidade. Rio de Janeiro: Bertrand Brasil. 2004.

IANNI, Octavio. O Mundo Agrário, In: A Era do Globalismo. Civilização Brasileira. Rio de Janeiro. 1996. 
LATOUR, Bruno. Jamais Fomos Modernos. Rio de Janeiro: Ed. 34. 1994.

LÉFÈBVRE, Henri. A Revolução Urbana. Belo Horizonte: Ed. UFMG, 1999(a).

A Cidade do Capital. Rio de Janeiro: DP\&A, 1999(b).

La Production de l'espace. Paris: Maspéro, 1986.

O Direito à Cidade. São Paulo: Centauro. 2001.

Problemas da Sociologia Rural e Perspectivas da Sociologia Rural. In: MARTINS, José de Souza (Org.).

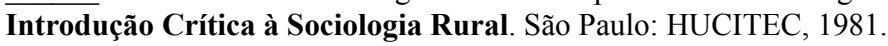

LENCIONI, Sandra. Uma nova determinação do urbano: o desenvolvimento do processo de metropolização do espaço. In: CARLOS, Ana Fani alessandri e LEMOS, Amália Inês Geraiges (orgs.). Dilemas Urbanos: novas abordagens sobre a cidade. São Paulo: Contexto. 2003.

LÉVY, Jacques. Le Tournant Géographique, Penser l'éspace pour lire le monde. Paris: Belin, 1999. 398 p.

MARX, Karl.; ENGELS, Friedrich. A Ideologia Alemã. São Paulo: Martins Fontes, 1998.

MASSEY, Doreen. Spaces of Politics. In: MASSEY, Doreen; ALLEN, John; SARRE, Philip. Human Geography Today. Cambridge/Oxford: Polity Press/Blackwell Publishers Ltd, 1999.p. 279-294.

MOREIRA, Roberto José e GAVÍRIA, Margarita Rosa. Territorialidades, Ruralidades e Assimetrias de poder. Estudos, Sociedade e Agricultura. Rio de Janeiro: CPDA-UFRRJ, n. 18, abril, 2002, pp 47-72.

MOREIRA, Roberto José. Cultura, Política e o Mundo Rural na Contemporaneidade. Estudos, Sociedade e Agricultura. Rio de Janeiro: CPDA-UFRRJ, n. 20, abril, 2003, pp 113-143.

Economia Política da Sustentabilidade: uma perspectiva neo-marxista. In: COSTA, Luiz F. C. BRUNO, Regina, MOREIRA, Roberto J. Mundo Rural e Tempo Presente. Rio de Janeiro: Mauad. 1999.

MOREIRA, Roberto José. Identidades Sociais em Territórios Rurais Fluminenses. In: MOREIRA, Roberto José (org.). Identidades Sociais, ruralidades no Brasil contemporâneo. Rio de Janeiro: DP\&A. 2005.

MORIN, Edgar. Ciência com Consciência. Rio de Janeiro: Bertrand Brasil, 2000.

La Métamorphose de Plozevet. Paris: Fayard, 1967.

O Método 3. O Conhecimento do Conhecimento. Porto Alegre: Sulina, 1999.

O método 4. As Idéias. Porto Alegre: Sulina, 2001.

O Método 5. A Humanidade da Humanidade. Porto Alegre: Sulina, 2002.

OLIVEIRA, Ariovaldo Umbelino. A Longa marcha do Campesinato Brasileiro: movimentos sociais, conflitos e reforma agrária. Estudos Avançados. São Paulo: USP, v. 15, n. 43, p. 185-206. set-dez. 2001.

A Agricultura Camponesa no Brasil. Contexto. São Paulo. 1991.

POULLE, François e GORGEU, Yves,. Essai Sur L'urbanité rurale: cinq territoires ruraux, leurs sérments et leurs modes de gouvernèment Paris. Syros. 1997.

RUA, João. Retomando Algumas Idéias. In: RUA, João (coord.). Quissamã Em Busca de Novos Caminhos. Rio de Janeiro: UERJ, Departamento de Geografia, 2000. 172 p. p. 153-159.

Urbanidades e Novas Ruralidades no Estado do Rio de Janeiro: Algumas Considerações Teóricas. IN: MARAFON, Gláucio José e RIBEIRO, Marta Foeppel (orgs.) Estudos de Geografia Fluminense. Rio de Janeiro: 
Urbanização em Áreas Rurais no Estado do Rio de Janeiro. In: MARAFON, Glaucio José; RIBEIRO, Marta Foeppel (Orgs.). Estudos de Geografia Fluminense. Rio de Janeiro: Livraria e Editora Infobook Ltda, 2002. 209 p. p. $27-42$.

SANTOS, Milton. A Natureza do Espaço, Técnica e Tempo, Razão e Emoção. São Paulo: HUCITEC, 1996.

A Urbanização Brasileira. São Paulo. HUCITEC. 1993. 157p.

Por Uma Geografia Nova. São Paulo: Hucitec, 1979.

Território e Sociedade. São Paulo: dação Perseu Abramo, 2000.

SCHNEIDER, Sérgio. As Transformações Recentes da Agricultura Familiar no RS, o caso da agricultura em tempo parcial. Revista FEE, v. 16, no 1.Porto Alegre. 1995.

SCHNEIDER, Sérgio. A Abordagem Territorial do desenvolvimento Rural e suas Articulações Externas.I Fórum Internacional Território, desenvolvimento Rural e Democracia. Fortaleza, Ceará, 16-19 de nov. 2003.

SMITH, Neil. Desenvolvimento Desigual. Rio de Janeiro. Editora Bertrand Brasil S.A. 1988.

SOROKIN, Pitirin A, ZIMMERMAN, Carlo, GALPIN, Charles. Diferenças fundamentais entre o mundo rural e o urbano. In: MARTINS, José de Souza. Introdução Crítica à Sociologia Rural. São Paulo: Hucitec, p. 198-224. 1986.

SPOSITO. Maria Encarnação Beltrão. A Urbanização da Sociedade: reflexes para um debate sobre as novas formas espaciais. In: DAMIANI, Amélia Luisa, CARLOS, Ana Fani Alessandri, SEABRA, Odette Carvalho de Lima. O espaço no fim do século: a nova raridade. São Paulo: Contexto, 1999.

VEIGA, José Eli da. A dimensão Rural do Brasil. Estudos, Sociedade e Agricultura. Rio de Janeiro: CPDAUFRRJ, n. 12, abril, 2004, pp 71-94.

VEIGA, José Eli da. O Brasil Rural ainda não encontrou seu eixo de desenvolvimento. Estudos Avançados. São Paulo: USP, v. 15, n. 43, p. 101-120. set-dez. 2001.

VEIGA, José Eli. A Face Rural do Desenvolvimento: natureza, território e agricultura. Porto Alegre: ed. Universidade/UFRGS, 2000.

WIRTH, Louis. O Urbanismo como Modo de Vida. In: VELHO, Otávio Guilherme (org.). O Fenômeno Urbano. Rio de Janeiro: Zahar Editores, 1976. 133 p. p. 90-113 